\title{
Article \\ Enhanced Activity and Sustained Release of Protocatechuic Acid, a Natural Antibacterial Agent, from Hybrid Nanoformulations with Zinc Oxide Nanoparticles
}

\author{
Khaled AbouAitah ${ }^{1,2, *}$, Urszula Piotrowska ${ }^{3}{ }^{\circledR}$, Jacek Wojnarowicz $\left.{ }^{1}{ }^{(}\right)$, Anna Swiderska-Sroda ${ }^{1}$, \\ Ahmed H. H. El-Desoky ${ }^{4}$ and Witold Lojkowski ${ }^{1, *(\mathbb{D}}$ \\ 1 Laboratory of Nanostructures and Nanomedicine, Institute of High Pressure Physics, Polish Academy of \\ Sciences, Sokolowska St. 29/37, 01-142 Warsaw, Poland; jacek.wojnarowicz@tlen.pl (J.W.); \\ a.swiderska-sroda@labnano.pl (A.S.-S.) \\ 2 Medicinal and Aromatic Plants Research Department, Pharmaceutical and Drug Industries Research Division, \\ National Research Centre (NRC), 33 El-Behouth St., Dokki, Giza 12622, Egypt \\ 3 Department of Biomaterials Chemistry, Chair of Analytical Chemistry and Biomaterials, Faculty of Pharmacy, \\ Medical University of Warsaw, 1 Banacha St., 02-097 Warsaw, Poland; upiotrowska@wum.edu.pl \\ 4 Pharmacognosy Department, Pharmaceutical Industries Research Division, National Research Centre, \\ 33 El-Behouth St., Dokki, Giza 12622, Egypt; wasseif@yahoo.com \\ * Correspondence: k.abouaitah@labnano.pl (K.A.); w.lojkowski@labnano.pl (W.L.); \\ Tel.: +48-22-888-0429 (K.A. \& W.L.) or +48-22-632-4302 (K.A. \& W.L.); Fax: +48-22-632-4218 (K.A. \& W.L.)
}

\section{check for} updates

Citation: AbouAitah, K.; Piotrowska, U.; Wojnarowicz, J.; Swiderska-Sroda, A.; El-Desoky, A.H.H.; Lojkowski, W. Enhanced Activity and Sustained Release of Protocatechuic Acid, a Natural Antibacterial Agent, from Hybrid Nanoformulations with Zinc Oxide Nanoparticles. Int. J. Mol. Sci. 2021, 22, 5287. https://doi.org/ $10.3390 /$ ijms 22105287

Academic Editor: Stefano Giovagnoli

Received: 29 March 2021

Accepted: 30 April 2021

Published: 18 May 2021

Publisher's Note: MDPI stays neutral with regard to jurisdictional claims in published maps and institutional affiliations.

Copyright: (c) 2021 by the authors. Licensee MDPI, Basel, Switzerland. This article is an open access article distributed under the terms and conditions of the Creative Commons Attribution (CC BY) license (https:// creativecommons.org/licenses/by/ $4.0 /)$.

\begin{abstract}
Hybrid nanostructures can be developed with inorganic nanoparticles (NPs) such as zinc oxide $(\mathrm{ZnO})$ and natural antibacterials. $\mathrm{ZnO}$ NPs can also exert antibacterial effects, and we used them here to examine their dual action in combination with a natural antibacterial agent, protocatechuic acid (PCA). To produce hybrid nanoformulations, we functionalized $\mathrm{ZnO}$ NPs with four types of silane organic molecules and successfully linked them to PCA. Physicochemical assessment confirmed PCA content up to $\sim 18 \%$ in hybrid nanoformulations, with a PCA entrapment efficiency of $\sim 72 \%$, indicating successful connection. We then investigated the in vitro release kinetics and antibacterial effects of the hybrid against Staphylococcus aureus. PCA release from hybrid nanoformulations varied with silane surface modification. Within $98 \mathrm{~h}$, only $8 \%$ of the total encapsulated PCA was released, suggesting sustained long-term release. We used nanoformulation solutions collected at days 3, 5, and 7 by disc diffusion or $\log$ reduction to evaluate their antibacterial effect against $S$. aureus. The hybrid nanoformulation showed efficient antibacterial and bactericidal effects that also depended on the surface modification and at a lower minimum inhibition concentration compared with the separate components. A hybrid nanoformulation of the PCA prodrug and ZnO NPs offers effective sustained-release inhibition of $S$. aureus growth.
\end{abstract}

Keywords: $\mathrm{ZnO}$ nanoparticles; protocatechuic acid prodrug; natural agents; hybrid nanoformulation; delivery system; sustained release; antibacterial effect; Staphylococcus aureus

\section{Introduction}

As microorganisms exhibit an increasing and troubling resistance to drug therapies, including antibiotics, the search for new solutions has become urgent. The growing prevalence of resistant bacteria poses a global public health threat [1] as pathogens become adapted to the most frequently used antibiotics [2]. Novel strategies are needed, especially those that rely on alternative drug sources, including natural agents from plant-derived compounds [3]. These agents offer a cost-effective diversity of chemical structures that can serve as a basis for drug development.

Among the microbes best known for developing resistance is Staphylococcus aureus (S. aureus), gram-positive bacteria associated with high morbidity, mortality, and biofilm formation [4]. S. aureus is a common culprit in infections of the skin and soft tissue, urinary 
tract, and bloodstream and in infective endocarditis, osteomyelitis, pulmonary infections, gastroenteritis, and toxic shock syndrome [5,6]. Incidence of these infections continues to grow, affecting medical care costs because of prolonged hospitalization [7]. The antibiotic used in these infections depends on whether the pathogen is susceptible or resistant (i.e., methicillin-resistant $S$. aureus; MRSA). In such cases, first-line antibiotics include vancomycin or one of the cephalosporins [8-10], which carry a high risk of serious adverse effects (nephrotoxicity, hypotension, hypersensitivity reactions in case of vancomycin) and antibiotic resistance [10]. New and safe antimicrobial drugs are urgently needed.

Nanostructures of various forms and composition are attracting interest in this area because of the unique characteristics they offer. Various nanoparticles (NPs) have been investigational targets as nanoplatforms, including silver, zinc oxide $(\mathrm{ZnO})$, or titanium oxide NPs [11-14]. The US Food and Drug Administration lists ZnO NPs as "generally recognized as safe" and approved it under the category of food additives. These NPs are of special interest as a nanoplatform for drug delivery, especially because of their own antibacterial potential [15] arising from release of ionized zinc $\left(\mathrm{Zn}^{2+}\right)$. The mechanism underlying these antibacterial effects [16-18] may involve cell membrane disruption, followed by NP penetration and multiple intracellular effects, including destruction of the cell membrane and mediation of reactive oxygen species (ROS), which are involved in cellular toxicity and apoptosis $[16,19,20]$. To date, studies of these NPs have focused on their direct antibacterial potential, but interest has also turned to using ZnO NPs in combination with other known antibacterial agents in hybrid nanoformulations. Thus far, these NPs have been conjugated with ciprofloxacin for testing against bacteria with multi-drug resistance [21], bound to the glucan-binding protein to trigger ROS production [22], functionalized by association with gallic and caffeic acids $[23,24]$, and loaded with amoxicillin for use against several different bacterial species [25].

Among the 200,000 structures isolated from natural products are phenolic compounds with broad pharmacological activities, including in vivo and in vitro antibacterial effects. One of these phenolic compounds is the prodrug protocatechuic acid (3,4-dihydroxybenzoic acid, or PCA), which is found in fruits, vegetables, grains, herbs, and spices [26,27]. Because this compound is nontoxic at an orally therapeutic dose of $100 \mathrm{mg} / \mathrm{kg}$, it represents a promising natural prodrug [27]. Studies with many different bacterial species suggest that PCA has a broad antibacterial potential [28-31]. A few studies have assessed the use of different nanostructures for drug delivery with PCA, e.g., for cancers [32,33].

Here, we sought to leverage the established safety and antibacterial effects of PCA by combining it with modified ZnO NPs in a nanoformulation that offers a sustained-release effect. We also assessed whether surface modification and loading of PCA in these hybrid nanoformulations affect antibacterial efficiency of the hybrid compared with ZnO NPs alone. We are aware of no existing reports on the preparation of a PCA-functionalized $\mathrm{ZnO} N \mathrm{~N}$ hybrid to enhance antibacterial activity against $S$. aureus. To test the antibacterial potential of this construct rather than conduct traditional antibacterial tests, we used aqueous solutions with the aim of mimicking the environment where the drug would be released from these nanoformulations to exert its therapeutic action, if any. For this purpose, we first performed in vitro drug release experiments at predetermined times and then collected the resulting solutions to use for assessing antibacterial effects. Thus, the findings we obtained reflect the antibacterial effects of PCA release from a nanoformulation with $\mathrm{ZnO}$ NPs. The promise of this approach is that it could serve as a platform for targeted local delivery of these drugs to the infected tissue or organ, perhaps has an antibacterial coating, for focused therapeutic action.

\section{Results and Discussion}

Use of antibiotics as the main antibacterial agents against infection leads to significant adverse effects and antibiotic resistance [10], inspiring a search for new, safe alternatives. Here, we used advanced nanotechnology to evaluate the antibacterial effects of a nanoformulation containing an antibacterial prodrug and NPs. For this purpose, we modified $\mathrm{ZnO}$ 
NPs with different organic functionalities using a post-synthesis route of silane groups reacted with $\mathrm{ZnO}$ and then loaded with PCA, a naturally occurring phenolic compound. The $\mathrm{ZnO} N P s$, functionalized $\mathrm{ZnO} N P s$, and hybrid nanoformulations were then characterized by their physicochemical properties, and the nanoformulations were investigated for PCA release and antibacterial activity against $S$. aureus. The work is schematically represented in Scheme 1.

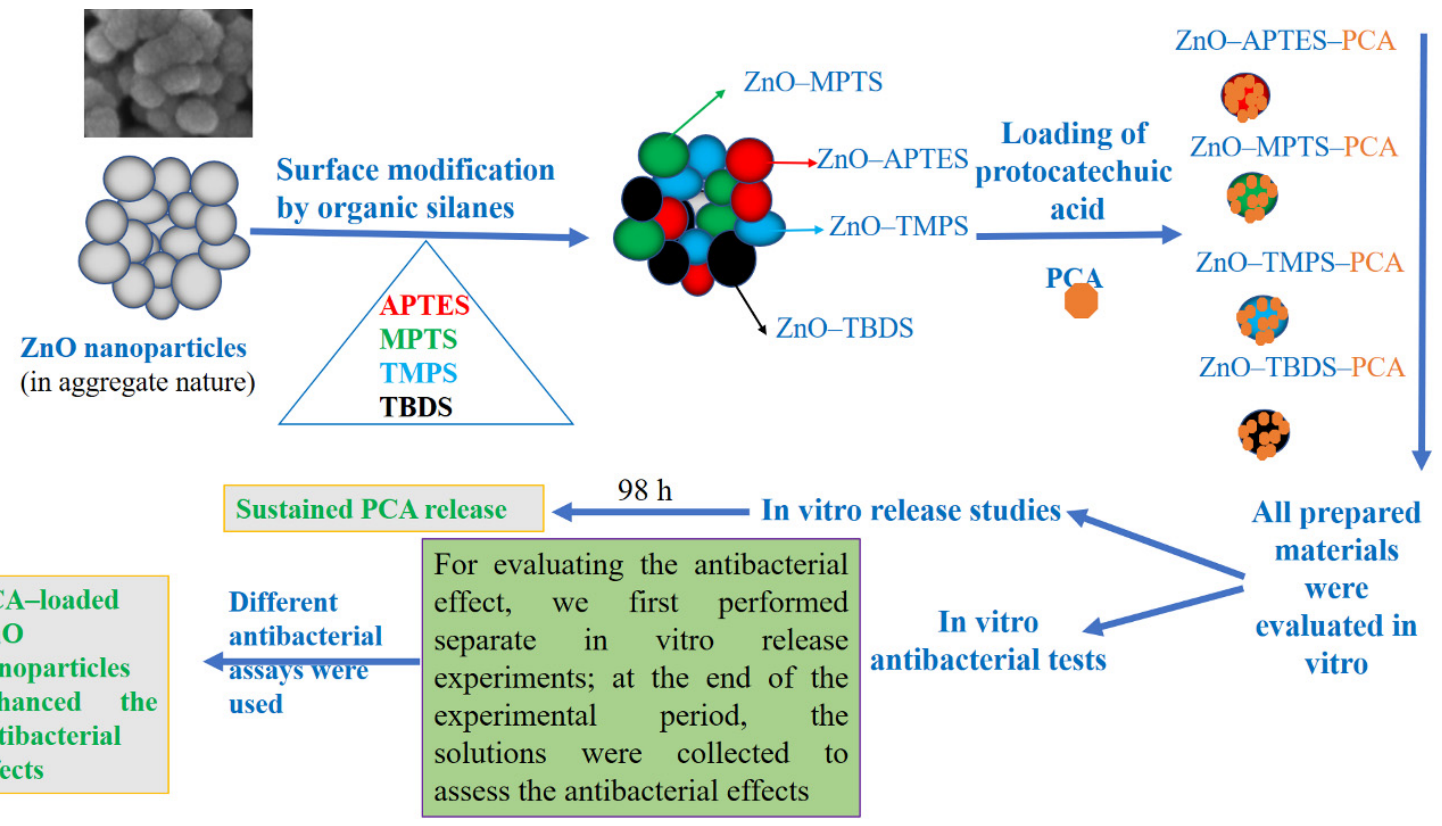

Scheme 1. Schematic representation of all synthesis stages and biological evaluations against bacteria for a delivery system for the PCA prodrug depending on ZnO NPs.

\subsection{Characterization of Materials}

\subsubsection{Morphological Structure and Elemental Measurements}

The SEM image (Figure 1) shows that pure ZnO NPs are nearly spherical to oval in shape, with an aggregated nature. This aggregation seems to be formed by very small NPs of about $50 \mathrm{~nm}$ that combine to yield larger aggregates. This morphology is concordant with what was described using the original synthesis method of Wojnarowicz et al. [34].

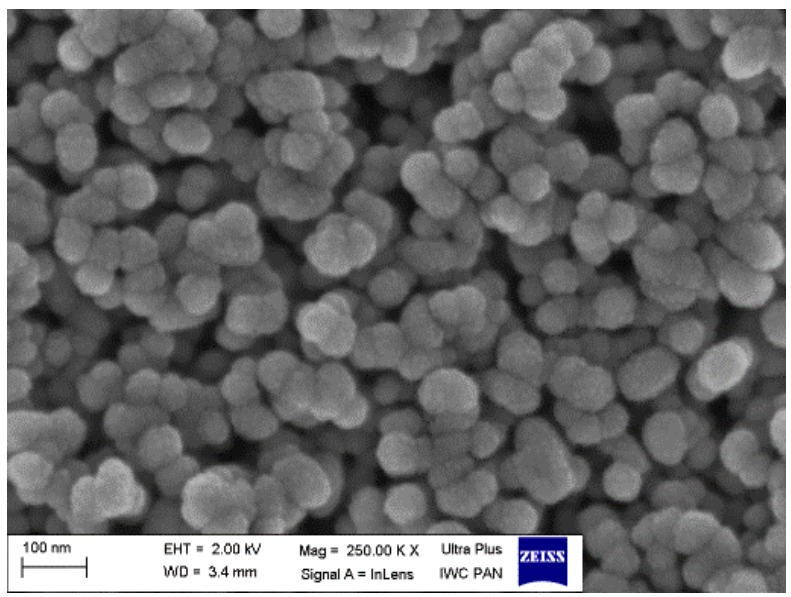

Figure 1. ZnO nanoparticles as visualized using FE-SEM.

We used EDX for the elemental analysis of materials at all preparation stages (Supplementary Materials Figure S1). As expected, the analysis showed that ZnO NPs consist of 
Zn and oxygen $(\mathrm{O})$. Additionally, about 15 at. \% of carbon (C) was detected. Earlier work indicated that some organic contribution from the alcohol used in solvothermal synthesis of a $\mathrm{ZnO}$ nano-powder may remain on the NP surface [35]. EDX analysis of surface-modified materials showed a carbon content at the level observed in pure ZnO NPs and below 1 at. $\%$ of silicon $(\mathrm{Si})$. Moreover, the presence of other elements was detected as follows: nitrogen $(\mathrm{N})$ in $\mathrm{ZnO}-\mathrm{APTES}$ because of APTES amino groups; sulfur (S) in ZnO-MPTS; phosphorus $(\mathrm{P})$ in $\mathrm{ZnO}-\mathrm{TMPS}$; and chlorine $(\mathrm{Cl})$ in $\mathrm{ZnO}-\mathrm{TBDS}$. The presence of $\mathrm{Si}$ and other specific elements $(\mathrm{N}, \mathrm{S}, \mathrm{P}$, and $\mathrm{Cl}$ ) confirmed successful surface functionalization and represented proof of the presence of silane groups on or in ZnO NPs.

\subsubsection{Thermal Analysis of Materials}

Figure 2 and Table 1 show thermal analysis results for the materials at each stage. Pure ZnO NPs and all functionalized NPs showed similar thermal properties. One can see an almost simultaneous decrease in the mass of the material, falling below $3 \mathrm{wt} \%$. Derivative thermogravimetric (DTG) curves indicate intensification of mass change kinetics in the temperature range of $250-500^{\circ} \mathrm{C}$ (Figure 2B) associated with the decomposition of organic substances in samples. As Table 1 shows, ZnO NPs and functionalized NPs did not differ significantly. Investigations of pure PCA showed that the prodrug decomposed during the experiment in $100 \%$ of the sample mass, with evidence of four process steps (Figure 2A,B). Mass loss was related to removing the water content (DTG peak centered at $\sim 80^{\circ} \mathrm{C}$ ), and decomposition with DTG peaks centered at $\sim 260^{\circ} \mathrm{C}, 375^{\circ} \mathrm{C}$, and $530{ }^{\circ} \mathrm{C}$. All hybrid nanoformulations demonstrated significant weight loss (about $20 \mathrm{wt} . \%$ ) compared to $\mathrm{ZnO}$ NPs and functionalized $\mathrm{ZnO}$ NPs (less than $3 \mathrm{wt}$.\%). Two stages of mass change were apparent during the heating to $800{ }^{\circ} \mathrm{C}$ (Figure 2A,B). The first appeared from RT up to $150^{\circ} \mathrm{C}$ and was connected with water evaporation from the powder surface. The next significant mass loss was observed at $350-400{ }^{\circ} \mathrm{C}$ depending on the material type. After that, practically no mass change was observed up to the end of the experiment.
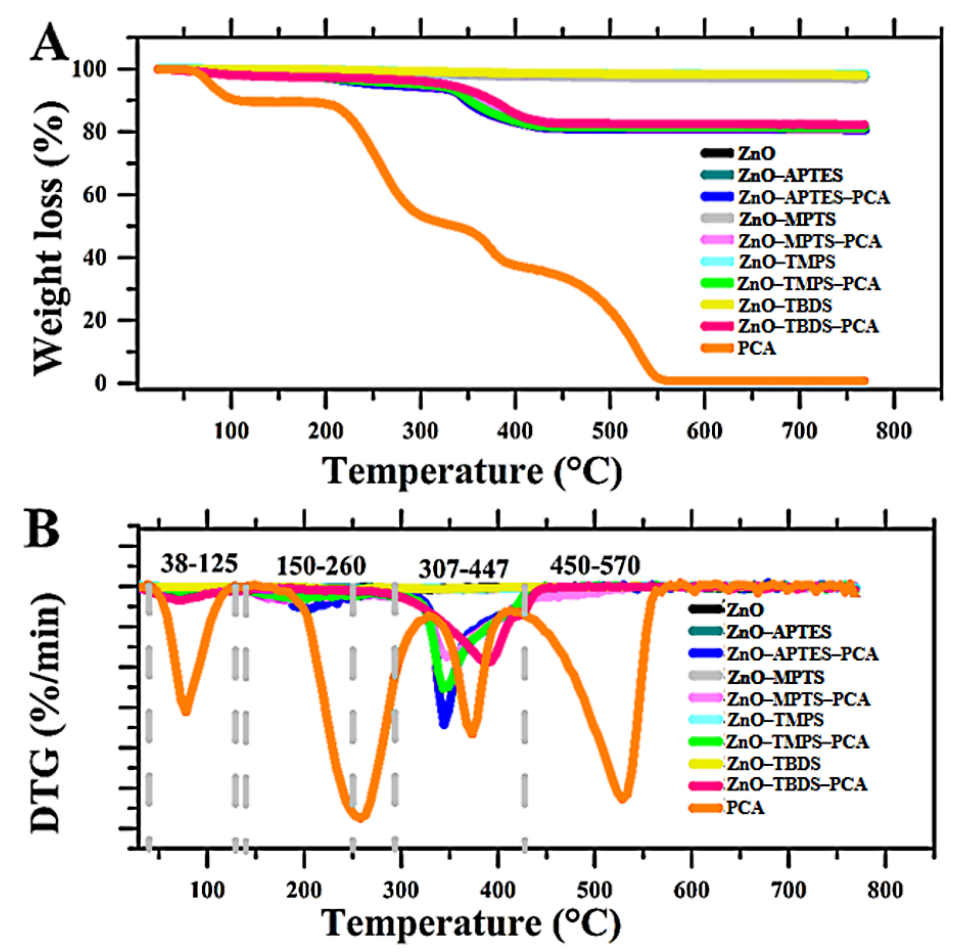

Figure 2. Thermal analysis results for materials at each stage by simultaneous thermal analysis, coupled with differential scanning calorimetry. (A) Weight loss measurements. (B) Derivative thermogravimetric (DTG) profiles. Materials were heated to $800{ }^{\circ} \mathrm{C}$ from RT at $10{ }^{\circ} \mathrm{C} / \mathrm{min}$ in a mixture of artificial air and helium flowing through the furnace chamber. 
Table 1. Thermogravimetric analysis and PCA loading properties for surface-modified $\mathrm{ZnO}$ nanoparticles.

\begin{tabular}{|c|c|c|c|}
\hline Material & Weight Loss (wt.\%) ${ }^{a}$ & $\begin{array}{l}\text { PCA Loading } \\
\text { Content (wt. } \%)^{b}\end{array}$ & $\begin{array}{l}\text { Entrapment } \\
\text { Efficiency }\end{array}$ \\
\hline $\mathrm{ZnO}$ & $2.55 \pm 0.8^{a}$ & & \\
\hline ZnO-APTES & $2.02 \pm 0.5^{a}$ & & \\
\hline ZnO-APTES-PCA & $19.6 \pm 0.5^{b}$ & $17.6 \pm 0.9^{\mathrm{a}}$ as PCA & $70.4 \pm 3.7^{\mathrm{a}}$ \\
\hline ZnO-MPTS & $2.5 \pm 0.4^{\mathrm{a}}$ & & \\
\hline ZnO-MPTS-PCA & $19.8 \pm 0.6^{b}$ & $17.2 \pm 1.1^{\mathrm{a}}$ as PCA & $68.8 \pm 4.4^{\mathrm{a}}$ \\
\hline ZnO-TMPS & $1.71 \pm 0.0^{\mathrm{a}}$ & & \\
\hline ZnO-TMPS-PCA & $19.5 \pm 1.2^{b}$ & $17.8 \pm 1.2^{\mathrm{a}}$ as PCA & $71.3 \pm 5^{a}$ \\
\hline $\mathrm{ZnO}-\mathrm{TBDS}$ & $2.0 \pm 0.4^{\mathrm{a}}$ & & \\
\hline ZnO-TBDS-PCA & $18.8 \pm 0.9^{b}$ & $16.8 \pm 0.8^{\mathrm{a}}$ as PCA & $67.1 \pm 3.3^{a}$ \\
\hline
\end{tabular}

${ }^{a}$ Weight calculated from thermogravimetry measurements. ${ }^{b, c}$ PCA loading content and entrapment efficiency calculated based on weight loss obtained from thermogravimetry. EE $(\%)=$ PCA amount that theoretically calculated - amount of PCA that actually calculated from weight loss/theoretically calculated $\times 100$. The superscript small letters indicate significant differences. The same letters indicate no significant differences, and different letters indicate a significance difference at $p<0.05$. For example, there are no significant differences between $\mathrm{ZnO}$ and $\mathrm{ZnO}-\mathrm{APTES}$, and they are denoted as "a." There are significant differences between $\mathrm{ZnO}$ and ZnOAPTES-PCA, and they marked by letters " $a$ " and " $b$ ", respectively.

\subsubsection{DSC Characterization of Materials}

DSC analysis of ZnO NPs and surface-functionalized NPs indicated an exothermic process during the experiments that was associated with mass loss (Figure 3). A broad exothermic peak centered at about $310{ }^{\circ} \mathrm{C}$ was detected in the case of ZnO NPs. After surface modification, the peaks were not symmetrical and shifted slightly up to a higher temperature compared to that for ZnO NPs. This difference most probably resulted from two overlapping processes: degradation of organic impurities in ZnO NPs and decomposition of silane components. For pure PCA, two endothermic peaks were present: a broad peak with a maximum at about $77^{\circ} \mathrm{C}$ related to water evaporation and a sharp peak at about $200^{\circ} \mathrm{C}$ related to PCA melting. Two exothermic signals followed, one that was small and broad with the extremum at about $375{ }^{\circ} \mathrm{C}$ and a sharper intense signal with a maximum at about $533^{\circ} \mathrm{C}$. These features are related to prodrug decomposition. We note that the DCS curve correlated with the kinetics of mass change observed on the DTG pictogram.

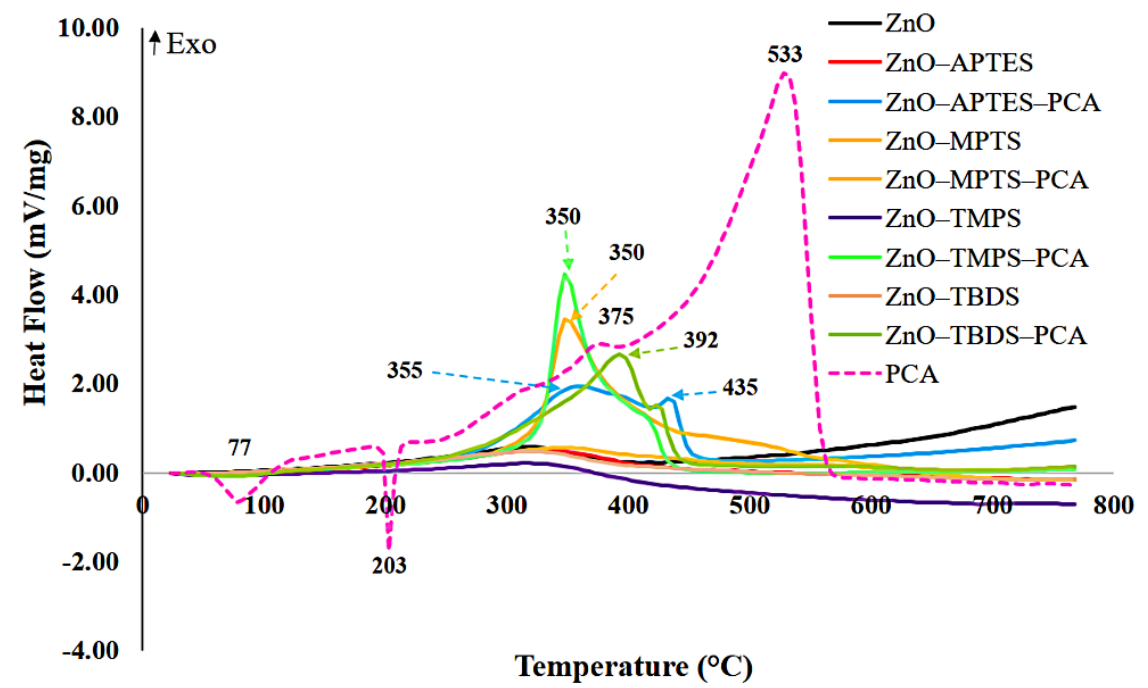

Figure 3. Differential scanning calorimetry analysis of ZnO NPs and surface-functionalized NPs. An exothermic process associated with mass loss is indicated. 
The DCS curves for nanoformulations presented a very weak endothermic peak arising from water evaporation at the beginning of the heating, but no endothermic peak related to melting of the prodrug was recorded. This observation suggests that PCA molecules present in nanoformulations have mainly an amorphous structure. For nanoformulations (ZnO-APTES-PCA, ZnO-MPTS-PCA, ZnO-TBDS-PCA and ZnO-TMPS-PCA), we observed an intense exothermic signal rising from two overlapping peaks. The first extremum of these non-symmetric peaks was present at $350-392{ }^{\circ} \mathrm{C}$ (depending on the sample) and reflected a decomposition process, as in the other materials. The second was seen at about $435^{\circ} \mathrm{C}$ and was probably associated with the intense signal registered at $533{ }^{\circ} \mathrm{C}$ for pure PCA. The reduction in the process temperature may be traced to the amorphous state of PCA in nanoformulations. As can be seen, DSC changes for all nanoformulation materials were tracked with DTG data.

\subsubsection{XRD Characterization}

The XRD technique is a good method for characterizing and identifying the crystalline structural state of NPs and for distinguishing changes in materials at different preparation stages. As Figure 4 shows, we detected no foreign phases in any of the unfunctionalized or functionalized NPs or nanoformulations. The diffraction pattern of ZnO NPs was characterized by a hexagonal phase, which is in agreement with the original synthesis reported by Wojnarowicz et al. (see JCPDS card number 36-1451) [34,36]. The main peaks of the 2theta angle and the "hkl" obtained for ZnO NPs, functionalized ZnO NPs, and nanoformulations included the following: $31.7 \AA$ (100), $34.4 \AA$ (002), $36.2 \AA$ (101), $47.5 \AA$ (102), $56.5 \AA$ (110), $63.0 \AA$ (103), $66.3 \AA$ (200), $68.0 \AA$ (112), $69.0 \AA$ (201), $72.6 \AA(004)$, $77.0 \AA$ (202), $81.4 \AA$ (104), and $89.6 \AA$ (203). No new peaks were detected for any of the functionalized NPs as a result of the organic functionalization process. Nanoformulations resulted in a new shift peak at $10.5 \AA$, corresponding to the main peak of the PCA pattern at $14.5 \AA$ (Figure 4). Although this peak was seen with small intensity compared to the peak with free PCA, it indicates a successful loading process and that a small fraction of the prodrug could be attached to the NP surface. These results are in good agreement with the DSC results, both indicating that the PCA prodrug was loaded mainly in a non-crystalline state into functionalized $\mathrm{ZnO}$ NPs. However, some small amount of PCA was located on the NPs surface in the crystalline form, as indicated by the small diffraction peak.

ZnO

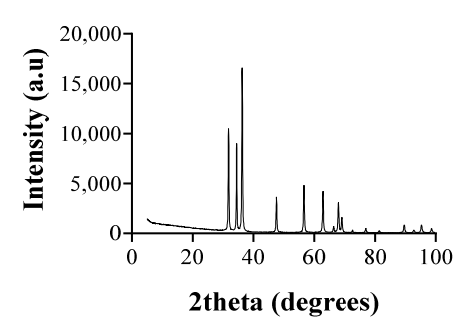

ZnO-APTES-PCA

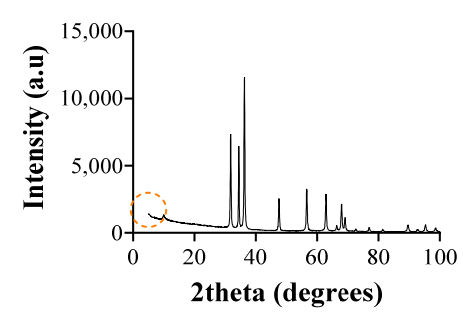

ZnO-APTES

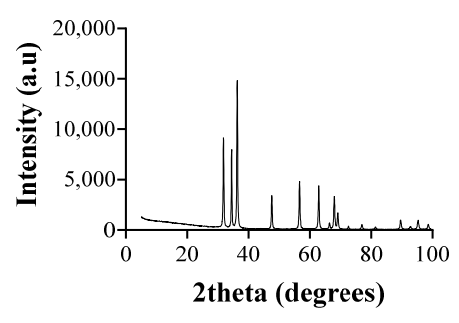

ZnO-MPTS

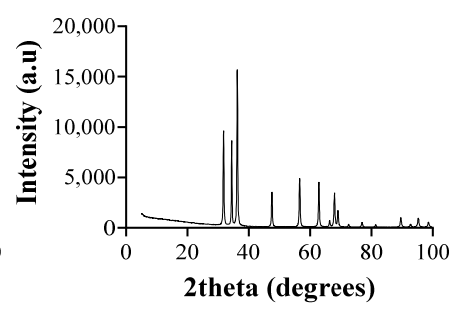

Figure 4. Cont. 

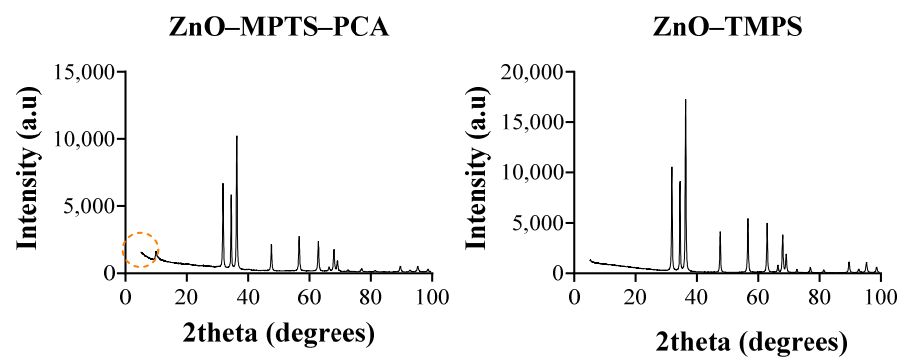

ZnO-TMPS-PCA
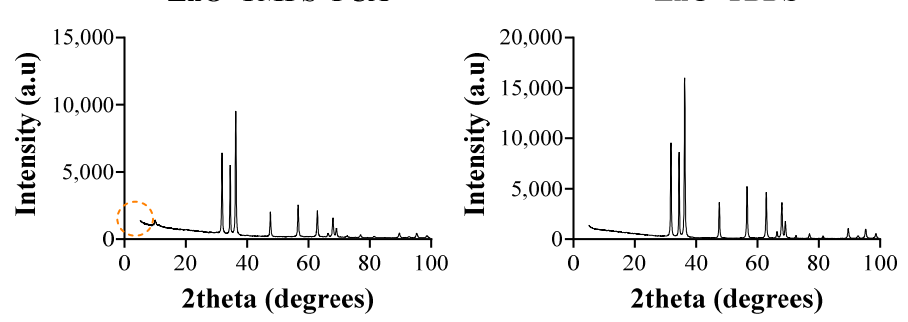

ZnO-TBDS-PCA
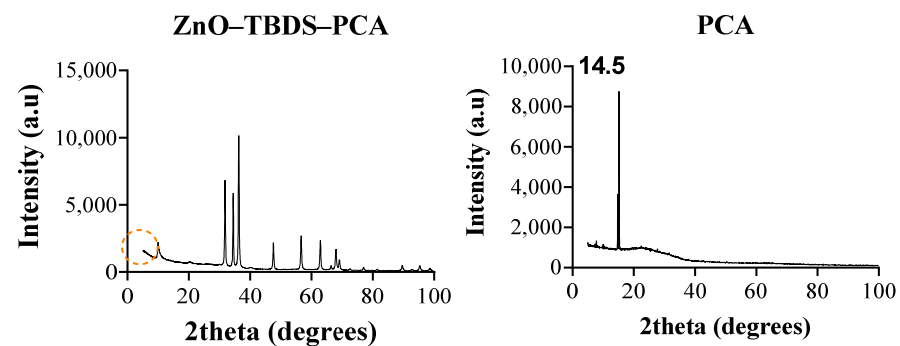

Figure 4. Results of X-ray diffraction analysis of dried powder materials for the PCA prodrug and before and after PCA loading in nanoformulations. The red-dotted circle indicates the presence of PCA in nanoformulations.

\subsubsection{FTIR-ATR Analysis}

Figure $5 \mathrm{~A}$ presents the spectra obtained for $\mathrm{ZnO}$ NPs and functionalized ZnO NPs. The $\mathrm{ZnO}$ NP spectra indicated a broad band arising from -OH groups, exhibiting stretching vibrations at $3100-3600 \mathrm{~cm}^{-1}$. Bands that were detected at a maximum of 2900 and $2867 \mathrm{~cm}^{-1}$ were associated with $\mathrm{C}-\mathrm{H}$ stretching vibrations, connected with post-processing impurities from ethylene glycol $\left(\mathrm{C}_{2} \mathrm{H}_{4}(\mathrm{OH})_{2}\right)$. Stretching vibrations from $\mathrm{C}=\mathrm{O}$ groups produced absorption bands of 1570 and $1417 \mathrm{~cm}^{-1}$, whereas asymmetrical stretching vibrations from C-O groups produced bands of $1083-1030 \mathrm{~cm}^{-1}$. We found no significant change between $\mathrm{ZnO}$ NP spectra before and after functionalization. However, peaks with relative intensities at 870 and $690 \mathrm{~cm}^{-1}$ observed for functionalized materials might be attributable to $\mathrm{Si}-\mathrm{O}$ bonds from silane functional groups, which usually appeared in this region [37]. Plausible explanations include the fact that the amount of silane in the samples was relatively small, as the thermogravimetry results indicated (Table 1), and that silane groups were presented inside NPs rather than on their surfaces, even below the limit of FTIR detection. FTIR spectra obtained for nanoformulations clearly gave proof of the presence of the prodrug (Figure $5 \mathrm{~B}$ ). The main bands detected for the pure prodrug $\left(1672,1606,1516,1416,1290,1100,930,895,767\right.$, and $\left.650 \mathrm{~cm}^{-1}\right)$ were also seen in nanoformulations. We identified a main peak of $1672 \mathrm{~cm}^{-1}$ that we could assign to the stretching of $\mathrm{C}=\mathrm{C}$ in PCA and a peak of $1290 \mathrm{~cm}^{-1}$ that we could assign to the carboxyl group $(C=O)$ stretching $[33,38]$. In addition, peaks in the region between $3662-1750 \mathrm{~cm}^{-1}$ corresponding to free PCA could be attributed to $\mathrm{O}-\mathrm{H}$ stretching vibrations and the PCA carboxyl group. This observation confirms that the main PCA molecules can be entrapped into nanoformulations ( $18 \mathrm{wt} . \%$ by thermogravimetry results), with some fraction of the 
PCA prodrug still attached to the particle surface. These results are consonant with the findings using XRD.
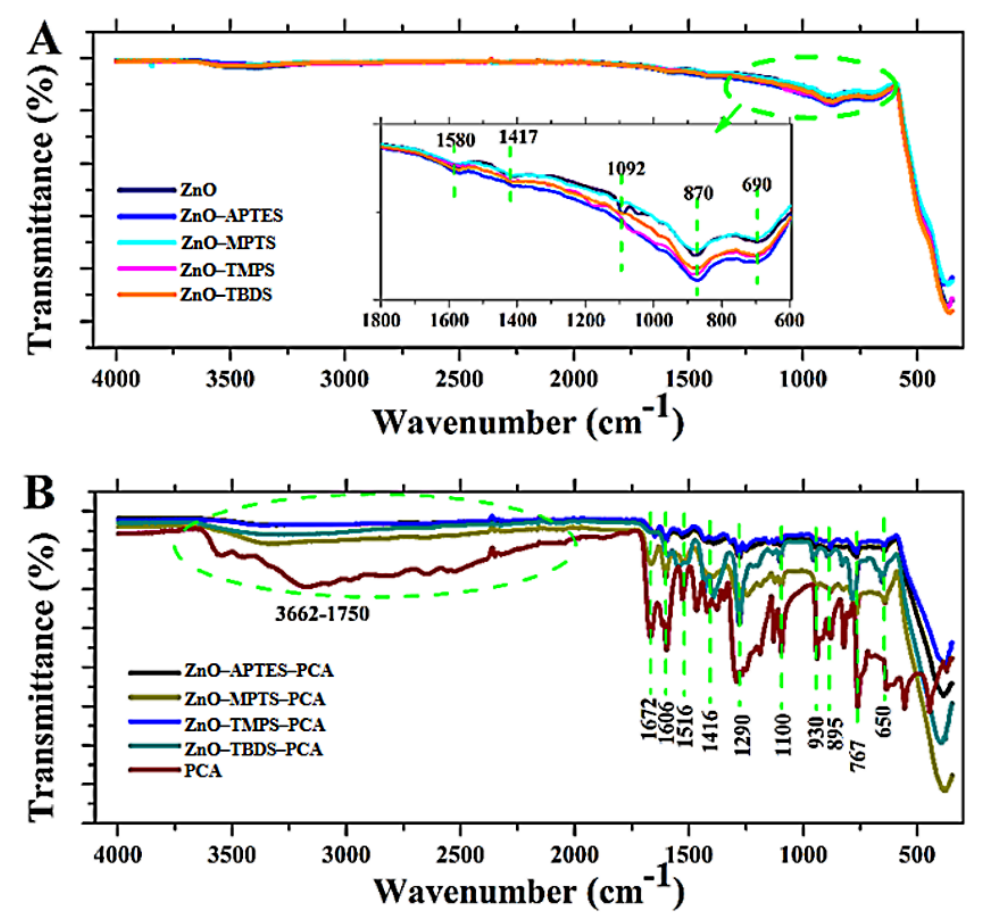

Figure 5. The spectra of ZnO NPs, modified ZnO NPs, and nanoformulations by Fourier-transform infrared spectroscopy. (A) ZnO NPs before and after surface modification. (B) Nanoformulations consisting of PCA and free PCA. In panel (A), the dotted green circle and lines show the changes following surface modifications with various silane groups compared to ZnO NPs. In panel (B), the dotted green circle and lines represent the detected new peaks in nanoformulations corresponding to free PCA.

\subsubsection{Zeta Potential Measurements of the Materials}

As Figure 6 shows, surface modifications and PCA loading led to changes in surface charges carried by NPs suspended in deionized water. Generally, ZnO NPs and functionalized NPs did not differ. The zeta potential of ZnO NPs was positive $(+28.8 \mathrm{mV})$, which is in agreement with previous studies [39-41]. Through further modification of the surface with APTES (ZnO-APTES) and TBDS ( $\mathrm{ZnO}-\mathrm{TBDS}$ ), the functionalized $\mathrm{ZnO}-\mathrm{NPs}$ had slightly higher positive charges of $30.8 \pm 0.8$ and $31.1 \pm 0.9 \mathrm{mV}$, respectively. This contrasts with functionalization using MPTS (ZnO-MPTS), which had negative charges $(-11.8 \pm 0.35 \mathrm{mV})$. The NPs functionalized with TMPS (ZnO-TMPS) exhibited smaller positive charges of about $5.1 \pm 0.2$. All nanoformulations had a negative zeta potential ranging from -13 to $-18 \mathrm{mV}$. The negative charges carried by nanoformulations were the result of the acidic nature of PCA, as we demonstrated with measurements of PCA alone, which showed a smaller negative zeta potential value (about $-5.9 \pm-0.9 \mathrm{mV}$ ). Overall, the results indicate that surface modification using various functional organic silanes and loading with PCA allowed for control of positive or negative charges on ZnO NPs in aqueous suspension. This finding is important because the $\mathrm{ZnO} N P$ surface affects other properties, such as cytotoxicity [40], by modulating $\mathrm{Zn}^{2+}$ ions release and antimicrobial effects [42]. 


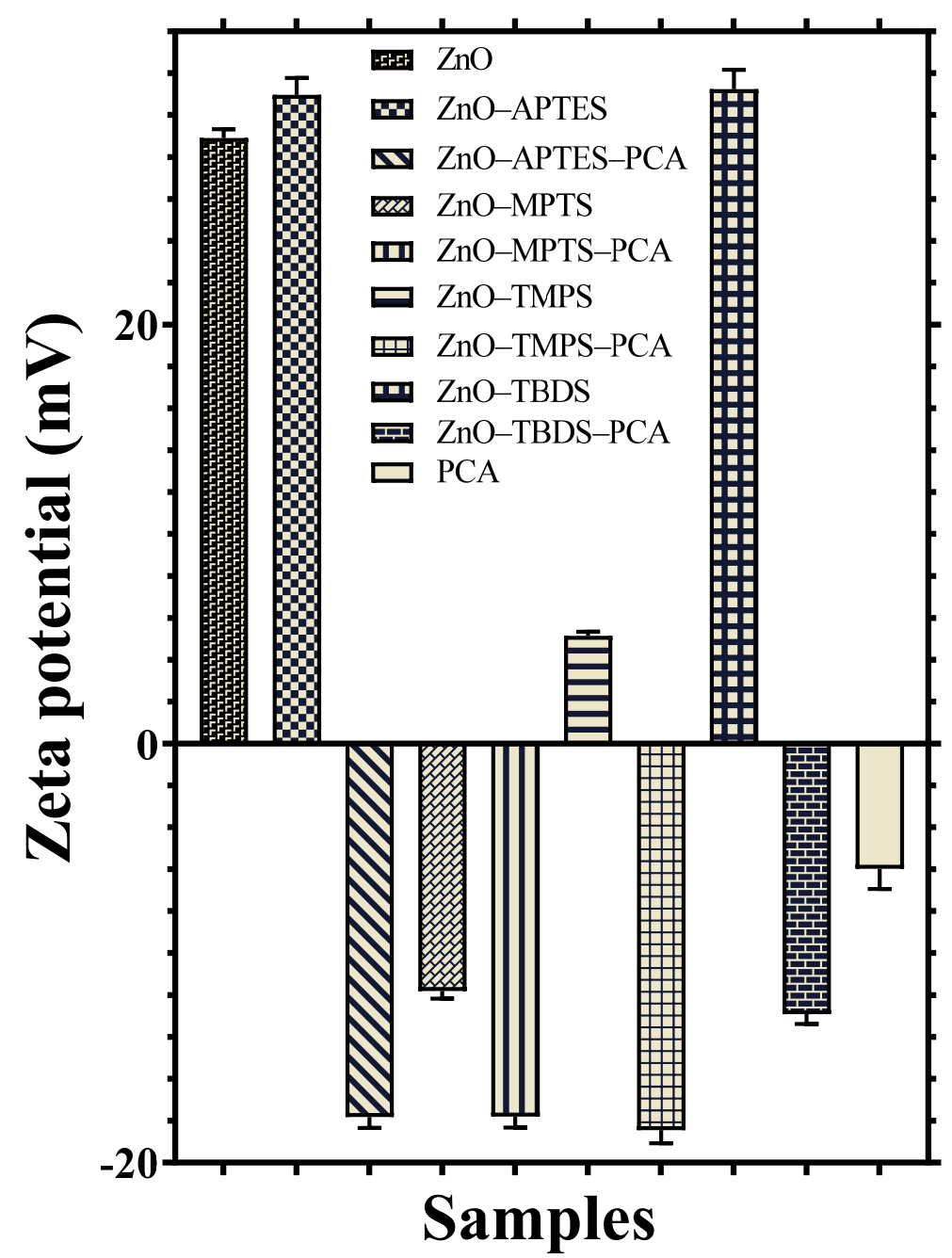

Figure 6. Zeta potential measurements in deionized water for all prepared materials before surface modification and after, along with PCA prodrug-loaded nanoformulations. The measurements were performed for all materials suspended in deionized water at $\mathrm{pH}$ 7.4.

\subsection{Drug Loading}

The loading and efficiency of PCA in nanoformulations was determined using the STA analysis. As Table 1 shows, the PCA loading content averaged between 16.8 to $17.8 \mathrm{wt} . \%$ depending on the surface functionalization of $\mathrm{ZnO}$. In addition, nanoformulations did not differ significantly from each other. The efficiency for PCA loading in nanoformulations reached $71.3 \%$, indicating successful preparation.

\subsection{In Vitro Release and Kinetics}

Release of PCA from hybrid nanoformulations can be modulated by organic functionality, further affecting antibacterial activity. The results suggest that surface functionalization influenced PCA release, as indicated by the release percentage shown in Figure 7 at the physiological $\mathrm{pH}$ of 7.4. The data demonstrated sustained release over time (almost $100 \mathrm{~h}$ ), with varied release values. Release from nanoformulations was obtained, from highest to lowest, as follows: ZnO-TBDS-PCA > ZnO-APTES-PCA > ZnO-TMPS-PCA $>$ ZnO-MPTS-PCA. However, the maximum percentage of PCA was only $~ 8 \%$ with the $\mathrm{ZnO}-\mathrm{TBDS}-\mathrm{PCA}$ nanoformulation within $98 \mathrm{~h}$. These results suggest that PCA release can be extended for a long period because only less than $10 \%$ was released, a feature that is crucial when long-term antibacterial exposure is required. Barahuie et al. [32] demonstrated that the release of PCA from magnesium/aluminum-layered double hydroxide nanocomposite is $\mathrm{pH}$-dependent, with a low release at $\mathrm{pH} 7.4$ compared to $\mathrm{pH}$ values 
of 5.3 and 4.8. They also found that the release reached over $80 \%$ within $70 \mathrm{~h}$. Similar results have been reported for PCA release from graphene oxide nanosheets, in which PCA release was $\mathrm{pH}$-responsive [33]. The current published findings demonstrate a high release at $\mathrm{pH} 4.8$ compared to 7.4 , along with more than $30 \%$ released at $\mathrm{pH} 7.4$ for $50 \mathrm{~h}$ [33]. Thus, the available data suggest that ZnO NPs of varying functionalization highly control PCA release. A plausible explanation is the strong interaction of PCA molecules with the functional surface groups distributed on modified $\mathrm{ZnO}$ NPs, making the release more controllable.

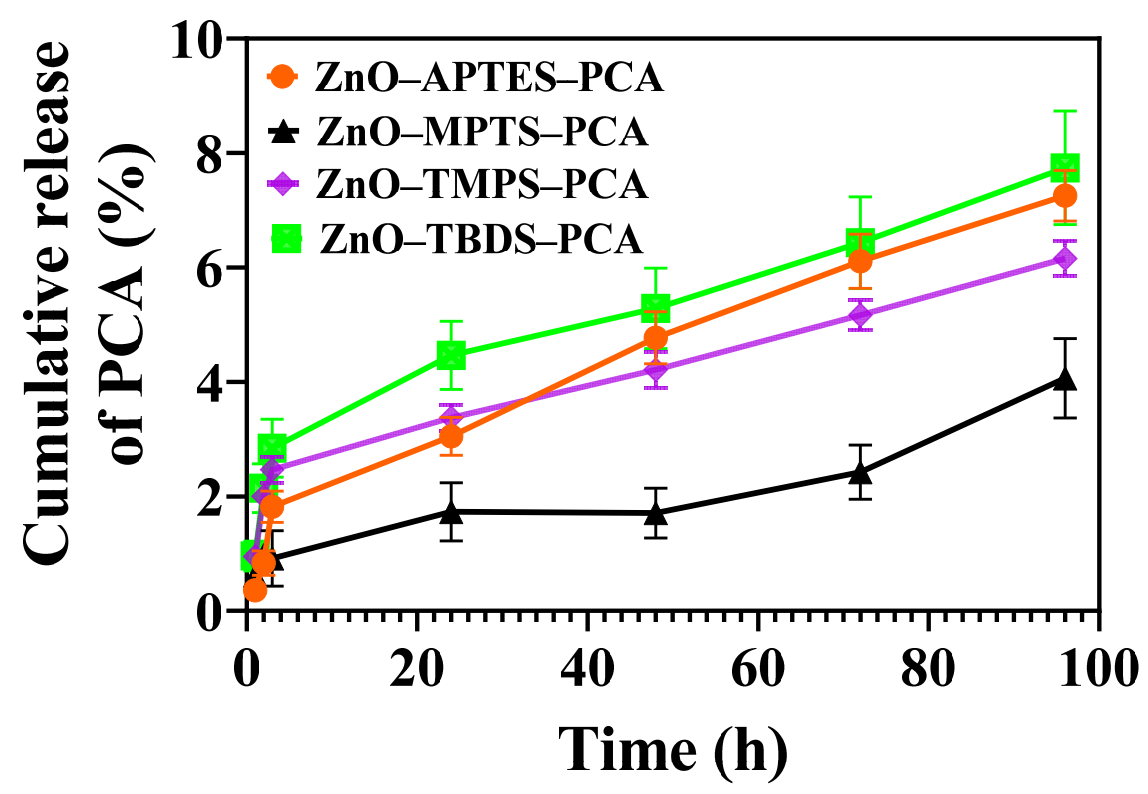

Figure 7. Release of the PCA prodrug from nanoformulations in the PBS medium (mean \pm standard).

The results of PCA release kinetics from nanoformulations are shown in Table 2. The PCA release from the ZnO-APTES-PCA nanoformulation best fit the Baker-Lonsdale model; that of the ZnO-MPTS-PCA nanoformulation best fit the Hickson-Crowell model; and the $\mathrm{ZnO}-\mathrm{TMPS}$ and $\mathrm{ZnO}-\mathrm{TBDS}-\mathrm{PCA}$ nanoformulations both fit best the KorsmeyerPeppas model with a lag. In the comparison of the RE percentage (RE\%), the values for RE\% PCA were ordered as follows: 5.3\% for ZnO-TBDS-PCA, 4.5\% for ZnO-APTES-PCA, $4.2 \%$ for $\mathrm{ZnO}-\mathrm{TMPS}-\mathrm{PCA}$, and $2.1 \%$ for $\mathrm{ZnO}-\mathrm{MPTS}-\mathrm{PCA}$. The MDT reached $47.1 \mathrm{~h}$ for ZnO-MPTS-PCA, $35.6 \mathrm{~h}$ for ZnO-APTES-PCA, $30.2 \mathrm{~h}$ for $\mathrm{ZnO}-T B D S-P C A$, and $30.2 \mathrm{~h}$ for $\mathrm{ZnO}-\mathrm{TMPS}-\mathrm{PCA}$. The $\mathrm{RR}$ was found to be $\sim 4.5 \% / \mathrm{h}$ for $\mathrm{ZnO}-\mathrm{TBDS}-\mathrm{PCA}$ and $\mathrm{ZnO}-\mathrm{TMPS}-$ $\mathrm{PCA}$ and $\sim 2.2 \% / \mathrm{h}$ for $\mathrm{ZnO}-\mathrm{APTES}-\mathrm{PCA}$ and $\mathrm{ZnO}-\mathrm{MPTS}-\mathrm{PCA}$. These results suggest that PCA releases from nanoformulations through diffusion kinetics and that changing the surface chemistry of $\mathrm{ZnO}$ NPs using various organic functionalities can alter the RE, MDR, and RR for the PCA prodrug. Earlier findings indicated that PCA can be kinetically differed based on the nanocarrier nanoformulation used. In this context, Barahuie et al. [32] found that the pseudo-second-order model best described the kinetic release of PCA from the layered double hydroxide nanocomposite material. This model also applied to PCA release from loaded gadolinium and gold-layered double hydroxide nanocomposite and graphene [33,43]. 
Table 2. In vitro release criteria of PCA released from nanoformulations prepared based on ZnO NPs modified with various organic functionalities in the PBS.

\begin{tabular}{|c|c|c|}
\hline Formulation & \multicolumn{2}{|c|}{ Release Characteristics } \\
\hline \multirow{5}{*}{ ZnO-APTES-PCA } & Best-fitting model & Baker-Lonsdale \\
\hline & RE & 4.5 \\
\hline & MDT & 35.6 \\
\hline & $\mathrm{RR}$ & 0.2 \\
\hline & $\mathrm{R}^{2}$ & 0.9901 \\
\hline \multirow{5}{*}{ ZnO-MPTS-PCA } & Best-fitting model & Hickson-Crowell \\
\hline & RE & 2.1 \\
\hline & MDT & 47.1 \\
\hline & RR & 0.2 \\
\hline & $\mathrm{R}^{2}$ & 0.9236 \\
\hline \multirow{5}{*}{ ZnO-TMPS-PCA } & Best-fitting model & Korsmeyer-Peppas with a lag \\
\hline & RE & 4.2 \\
\hline & MDT & 30.2 \\
\hline & RR & 0.4 \\
\hline & $\mathrm{R}^{2}$ & 0.9397 \\
\hline \multirow{5}{*}{ ZnO-TBDS-PCA } & Best-fitting model & Korsmeyer-Peppas with a lag \\
\hline & RE & 5.3 \\
\hline & MDT & 30.2 \\
\hline & RR & 0.5 \\
\hline & $\mathrm{R}^{2}$ & 0.9484 \\
\hline
\end{tabular}

RE, release efficiency, \%; MDT, mean dissolution time, h; RR, release rate, \%h.

\subsection{Antibacterial Evaluations}

2.4.1. In Vitro Bacterial Activity by the Log Reduction Assay

During the first stage of our investigation, we used the log reduction assay to evaluate $\mathrm{ZnO}$ NPs activity against $S$. aureus (Figure 8) and identified a significant antibacterial effect of NPs alone and of nanoformulations. The viable bacteria count decreased by log 6 to $\log 7$ after three days of incubation compared to the negative control sample and by $\log 2$ to $\log 3$ compared to PCA alone. After five days of incubation, a bactericidal effect was seen for most of the samples. However, in the cases of functionalized particles of the $\mathrm{ZnO}-\mathrm{TBDS}$ and $\mathrm{ZnO}-\mathrm{APTES}-\mathrm{PCA}$ nanoformulation, there was a slight bacterial growth along with the $\log 6$ to $\log 7$ reduction in viable bacteria counts. After seven days of release, no bacterial growth was noted for any of the tested materials. One possible explanation for that finding is $\mathrm{Zn}^{2+}$ ion release from $\mathrm{ZnO}$ NPs. Cierech et al. [44] used optical emission spectrometry with inductively coupled plasma to assess $\mathrm{Zn}^{2+}$ ion release from $\mathrm{ZnO}$ NPs (as used in our study). They found ion release even from a ZnO-PMMA nanocomposite at $>4 \mathrm{mg} / \mathrm{L}$. These results suggest that the significant antibacterial effect arises from the combination of released $\mathrm{Zn}^{2+}$ and PCA, leaving no statistically significant difference between $\mathrm{ZnO}$, functionalized $\mathrm{ZnO}$ NPs, and nanoformulations. ZnO NPs are well-known for their unique antimicrobial activities in various microbial infections [16] and can act on bacteria by different mechanisms, including by triggering ROS damage to the cell and direct effects on the cell membrane $[45,46]$. 

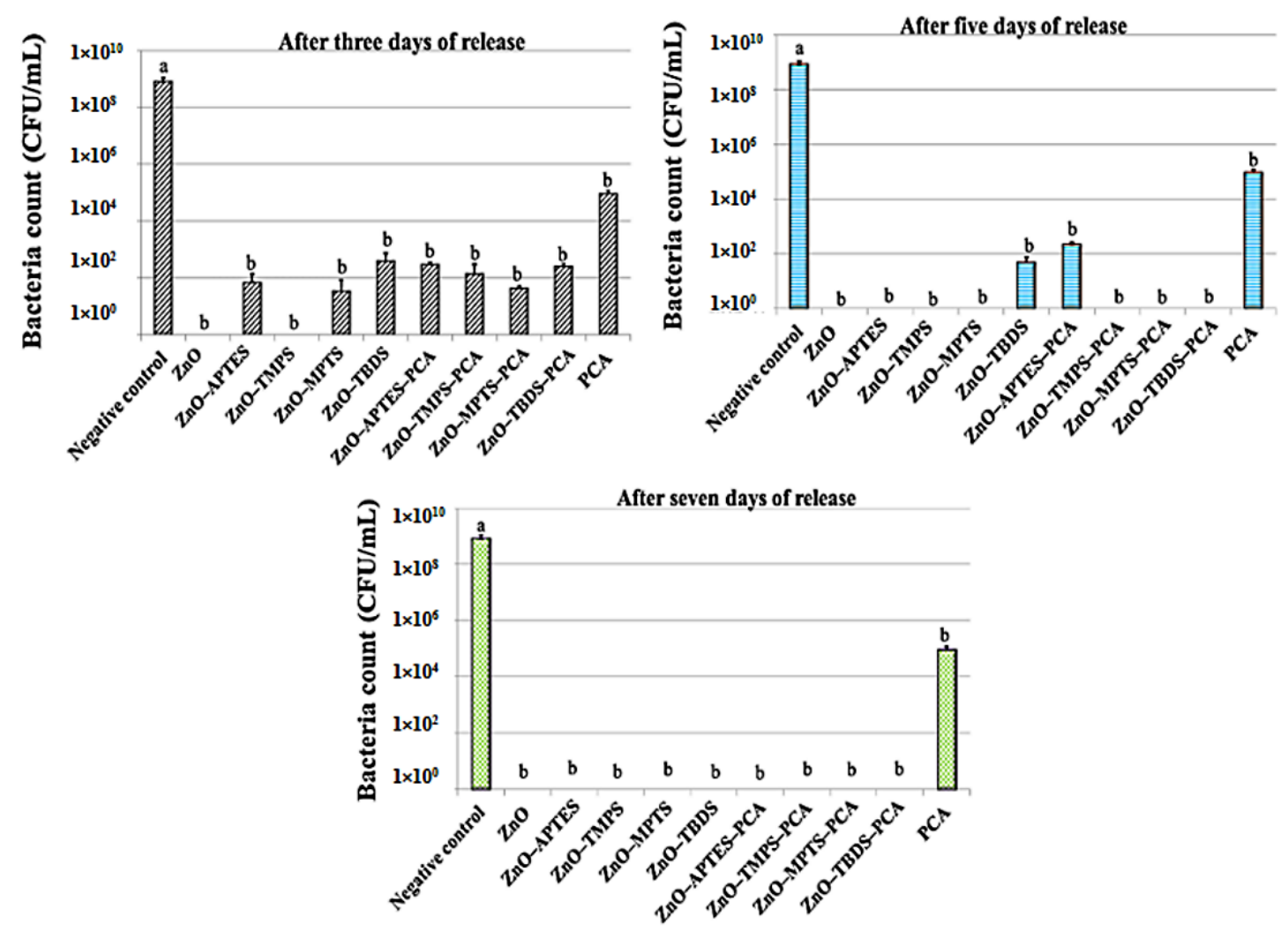

Figure 8. Results of the log reduction assay of ZnO NPs, surface-modified NPs, nanoformulations, PCA antimicrobial activity of the solutions (supernatants) obtained after three, five, and seven days against $S$. aureus. Columns labeled with different letters $(a, b)$ had significantly different average values $(p \leq 0.05)$. Materials marked by the same letter (for instance, "a") displayed no significant differences. Materials marked with different letters (for instance, "a" for one material and " $b$ " for another material) displayed significant differences.

\subsubsection{In Vitro Bacterial Activity by the Disc Diffusion Method}

We used the agar disc diffusion method to evaluate antimicrobial activity of the tested supernatants obtained from solutions after release in the PBS buffer. Figure 9 shows the resulting antibacterial activity for the tested NPs, nanoformulations, and PCA after three and seven days of incubation at $37^{\circ} \mathrm{C}$ in the PBS. After three days of incubation, the most active were $\mathrm{ZnO} N P s$ (growth inhibition zone, $7.3 \mathrm{~mm}$ ), probably because of rapid $\mathrm{Zn}$ (II) release. The ZnO-APTES, ZnO-TBDS, ZnO-APTES-PCA, ZnO-TMPS-PCA, and ZnO-MPTS-PCA samples did not differ from one another, but did differ significantly from ZnO NPs $(p \leq 0.05)$.

After seven days of release, all of the treatments exhibited antimicrobial activity. Antimicrobial activity did not differ significantly in comparisons of ZnO-APTES and ZnO-APTES-PCA, of ZnO-TMPS and ZnO-TMPS-PCA, of ZnO-MPTS-PCA and ZnOTBDS and ZnO-TBDS-PCA. The observed antibacterial effect of ZnO NPs alone could be attributed to cell membrane disintegration or damage, genomic instability, and intracellular ROS production $[15,17,23,47]$. Moreover, we found statistically significant differences for the ZnO-MPTS $(6.7 \mathrm{~mm}$ ) and ZnO-MPTS-PCA nanoformulations $(8.3 \mathrm{~mm})$, with higher antimicrobial activity of the nanoformulation against $S$. aureus after seven days compared with $\mathrm{ZnO}$ NPs alone. 

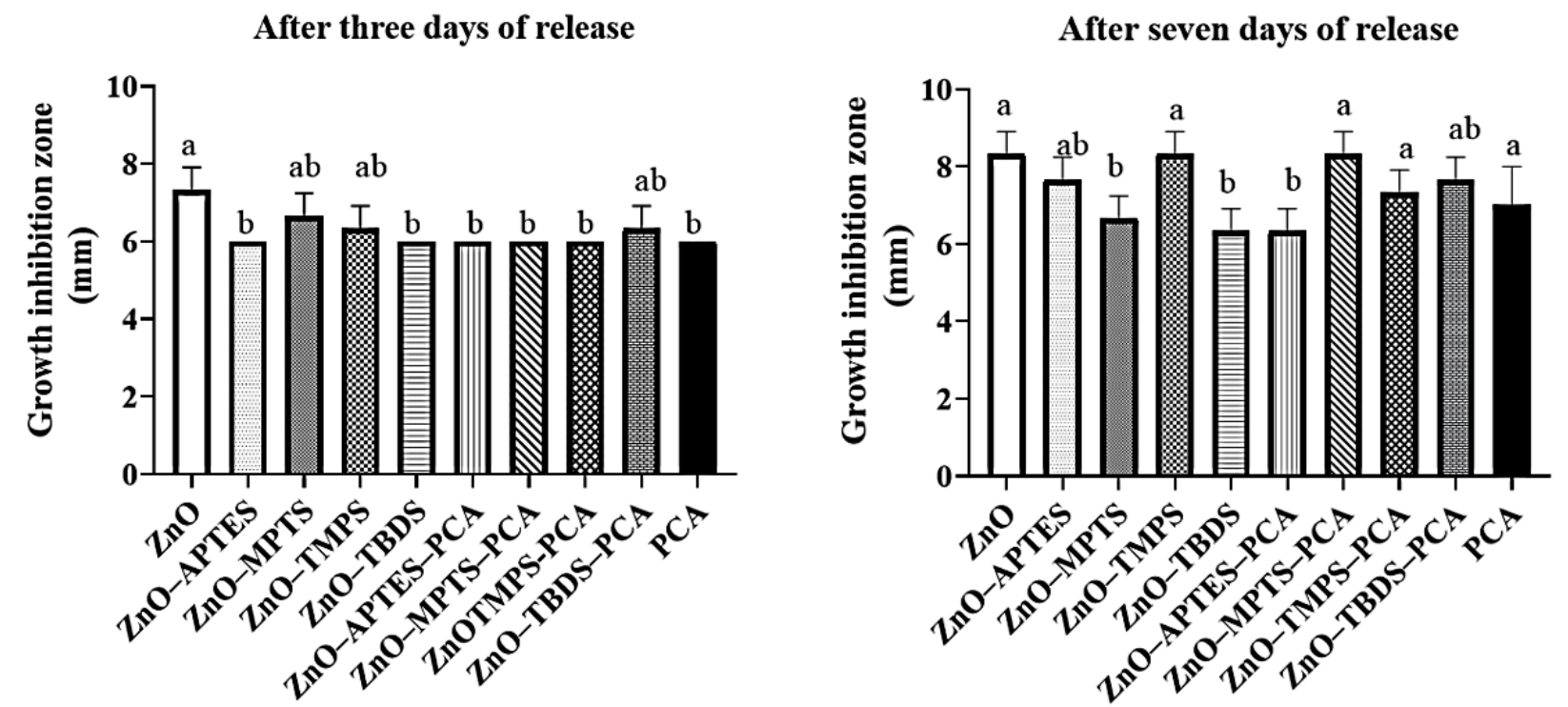

Figure 9. Antimicrobial activity of the solutions (supernatants) obtained after three and seven days of incubation of the tested materials at $37^{\circ} \mathrm{C}$ in the PBS. Columns labeled with different letters $(a, b)$ had significantly different average values $(p \leq 0.05)$. Materials marked by the same letter (for instance, "a") displayed no significant differences. Materials marked with different letters (for instance, " $a$ " for one material and " $b$ " for another material) displayed significant differences.

\subsubsection{In Vitro Bacterial Activity by MIC Determination}

The tested solution's supernatants of $\mathrm{ZnO}$, functionalized $\mathrm{ZnO} N \mathrm{Ns}$, PCA, and nanoformulations obtained after seven days of release were chosen for the biological tests because of their strong antimicrobial activities (Figure 8). The results are presented in Table 3. As the table shows, nanoformulations resulted in stronger antimicrobial activities vs. $\mathrm{ZnO}$ NPs (MIC, $2.07 \mathrm{mg} / \mathrm{mL}$ ) or free PCA (MIC, $2.50 \mathrm{mg} / \mathrm{mL}$ ). In case of ZnO-TMPS, ZnOMPTS, and ZnO-TBDS, the effective initial concentration was $4.15 \mathrm{mg} / \mathrm{mL}$. The reason that $\mathrm{ZnO}$ NPs had a greater effect than the modified NPs might be the presence of organic functionalization on the surface that delayed $\mathrm{Zn}^{2+}$ release from $\mathrm{ZnO}$ NPs. The expected effect of this would be decreased cytotoxicity [40], implying that surface modification can modulate cytotoxicity of ZnO NPs. Most of the nanoformulations decreased MIC to $1.03 \mathrm{mg} / \mathrm{mL}$ compared to other tested solutions. The phenolic structure of PCA covering the surface may not have allowed bacterial growth, and the $\mathrm{Zn}^{2+}$ ions from $\mathrm{ZnO}$ NPs may also have performed as expected. Lee et al. [23] assessed ZnO NPs functionalized with gallic acid, evaluating their antibacterial and antioxidant effects against MRSA. They found that gallic acid-loaded NPs enhanced antioxidant and antibacterial effects by reducing bacterial cell viability. Palanikumar et al. loaded amoxicillin into ZnO NPs and found enhanced antibacterial effects compared to ZnO NPs alone [25]. Furthermore, ciprofloxacinconjugated ZnO NPs also are antibacterial against clinically isolated MRSA [21]. The results from our study indicate that a high affinity of the PCA phenolic structure underlies its antibacterial selectivity and activity, along with additional effects of $\mathrm{Zn}$ ions on the bacterial cell membrane. 
Table 3. Biological activity of surface-modified ZnO NPs and nanoformulations consisting of the PCA prodrug.

\begin{tabular}{|c|c|c|c|c|c|}
\hline \multirow{3}{*}{ Material } & \multicolumn{5}{|c|}{ Concentration of $\mathrm{ZnO}$ NPs in the Initial Solution, $\mathrm{mg} / \mathrm{mL}$} \\
\hline & 8.33 & 4.15 & 2.07 & 1.03 & 0.51 \\
\hline & \multicolumn{5}{|c|}{ Turbidity of the Culture Medium } \\
\hline $\mathrm{ZnO}$ & - & - & - & + & + \\
\hline ZnO-APTES & - & - & + & + & + \\
\hline ZnO-TMPS & - & - & + & + & + \\
\hline $\mathrm{ZnO}-\mathrm{MPTS}$ & - & - & + & + & + \\
\hline ZnO-TBDS & - & - & + & + & + \\
\hline \multirow{5}{*}{ Material } & \multicolumn{5}{|c|}{ Concentration of ZnO NPs in the Initial Solution, $\mathrm{mg} / \mathrm{mL}$} \\
\hline & 8.33 & 4.15 & 2.07 & 1.03 & 0.51 \\
\hline & \multicolumn{5}{|c|}{ Equal to the Concentration of PCA in the Initial Solution, $\mathrm{mg} / \mathrm{mL}$} \\
\hline & 1.72 & 0.86 & 0.43 & 0.21 & 0.10 \\
\hline & \multicolumn{5}{|c|}{ Turbidity of the Culture Medium } \\
\hline ZnO-APTES-PCA & - & - & - & + & + \\
\hline ZnO-TMPS-PCA & - & - & - & - & + \\
\hline ZnO-MPTS-PCA & - & - & - & - & + \\
\hline ZnO-TBDS-PCA & - & - & - & - & + \\
\hline Free PCA & $\begin{array}{c}\text { MIC: } \\
2.50 \mathrm{mg} / \mathrm{mL}\end{array}$ & & & & \\
\hline
\end{tabular}

+ , turbid broth, indicates bacterial growth; - , clear medium, indicates no bacterial growth.

\section{Materials and Methods}

\subsection{Synthesis of ZnO NPs and Surface Modification}

We synthesized ZnO NPs using a microwave-assisted solvothermal approach as previously described by Wojnarowicz et al. [34,35]. Four organic silanes were employed to functionalize the surface of ZnO NPs: 3-aminopropyltriethoxysilane (APTES; Sigma-Aldrich, St. Louis, MO, USA); a solution of 3-(trihydroxysilyl)propyl methylphosphonate monosodium salt (TMPS; Santa Cruz Biotechnology, Dallas, TX, USA); and (3-mercaptopropyl)trimethoxysilane (MPTS) and 98\% tert-butyl(chloro) diphenyl-silane (TBDS; both from Arcos Organics, Geel, Belgium). To functionalize ZnO NPs, we added $1 \mathrm{~g}$ of ZnO NPs in toluene $(100 \mathrm{~mL})$ for APTES, MPTS, and TBDS, and in $18.2 \mathrm{M} \Omega$ ultrapure water $\left(100 \mathrm{~mL}\right.$; Milli-Q ${ }^{\circledR}$, Millipore, Darmstadt, Germany) for TMPS. The solutions were left under strong stirring for $10 \mathrm{~min}$; then, $0.7 \mathrm{~mL}$ of APTES, MPTS, TMPS, or TBDS were added dropwise. After adjustment of the stirring speed to $300 \mathrm{rpm}$, the solution was maintained for $24 \mathrm{~h}$ at room temperature (RT). After this step, the solutions were filtered and washed with ultrapure water several times to remove unreacted molecules, followed by $24 \mathrm{~h}$ of drying at $60^{\circ} \mathrm{C}$. The resulting modified NPs were designated as $\mathrm{ZnO} \neg-\mathrm{APTES}, \mathrm{ZnO}-\mathrm{MPTS}, \mathrm{ZnO}-\mathrm{TMPS}$, and $\mathrm{ZnO}-\mathrm{TBDS}$.

\subsection{PCA Prodrug Loading}

To prepare hybrid nanoformulations, PCA was loaded to functionalized ZnO NPs with a drug/carrier ratio of 1:3. For loading, we dissolved $100 \mathrm{mg}$ PCA (Sigma-Aldrich) in dimethyl sulfoxide (Tedia, Fairfield, OH, USA) and ethanol (Fisher Scientific, Loughborough, UK) in a 1:1 ratio. A total of $300 \mathrm{mg}$ of each functionalized $\mathrm{ZnO} \mathrm{NP}$ was added to this solution, followed by $24 \mathrm{~h}$ of stirring at RT and then evaporation in a Rotavap oven at $60^{\circ} \mathrm{C}$ (Büchi, Flawil, Switzerland). Next, we resuspended the resulting powder of PCA-loaded $\mathrm{NPs}$ in ultrapure water $(20 \mathrm{~mL})$, followed by evaporation for removal of any unloaded 
PCA, and repeated this process once more. The resulting product was dried in an oven for $12 \mathrm{~h}$ at $60^{\circ} \mathrm{C}$, and the hybrid nanoformulations yielded from this process were designated as ZnO-APTES-PCA, ZnO-MPTS-PCA, ZnO-TMPS-PCA, and ZnO-TBDS-PCA.

\subsection{Characterization Techniques}

To identify the resulting NPs at each stage, we used several techniques, including field emission (FE) scanning electron microscopy (SEM; Ultra Plus, Zeiss, Jena, Germany) coupled with energy dispersive X-ray spectroscopy (EDX) to characterize their morphology and perform elemental analysis. Samples used in SEM-EDX experiments were sputtered with gold. Powder X-ray diffraction (XRD; Almelo, Netherlands) using $\mathrm{CuK} \alpha$ radiation ( $2 \theta$ range of $10,100^{\circ}$ ) was employed to identify the crystalline state. To identify surface functional groups, we applied Fourier-transform (FT) infrared (IR) spectroscopy using a Bruker Tensor 27 IR instrument (Bruker Corporation, Billerica, MA, USA) implemented with attenuated total reflectance using a Bruker Platinum ATR-Einheit A 255. To evaluate the thermal stability of the materials at each of the three preparation stages, we performed simultaneous thermal analysis (STA; 449 F1 Jupiter ${ }^{\circledR}$, NETZSCH-Feinmahltechnik GmbH, Selb, Germany) using a combination of differential scanning calorimetry (DSC) and thermogravimetry. The samples were heated to $800{ }^{\circ} \mathrm{C}$ from RT at $10^{\circ} \mathrm{C} / \mathrm{min}$ in a mixture of artificial air and helium flowing through the furnace chamber. All experiments were performed under the same conditions. To measure the zeta potential of the particles in a deionized water suspension of each NP type, we used a Zetasizer Nano-ZS ZEN 3600 (Malvern Instruments Ltd., Malvern, UK).

\subsection{In Vitro Release}

Throughout the experiment, the powders from nanoformulations were placed with the phosphate-buffered saline (PBS) in glass bottles maintained at $37^{\circ} \mathrm{C}$ in a water bath while being shaken at $150 \mathrm{rpm}$ (shaker type 357, Elpin+, Lubawa, Poland). Up to $98 \mathrm{~h}$, we would withdraw an aliquot from each bottle at predetermined timepoints and replace the withdrawn volume with fresh PBS buffer. After the aliquots were centrifuged to separate nanoformulation particles, the resulting supernatants were placed in new vials and stored at $4{ }^{\circ} \mathrm{C}$ until the UV-vis analysis. Absorbance was measured at $280 \mathrm{~nm}$ using the UV-vis technique (U-2900 spectrophotometer, Hitachi High-Technologies Corporation, Tokyo, Japan). Several measurements were performed for each sample, and the cumulative drug release of PCA from nanoformulations was calculated based on the following Equations (1) and (2):

$\%$ of mass released at time $t=($ mass $(t) /$ total mass of the drug in the nanoformulation $) \times 100$

$$
\text { cumulative } \%=\text { mass }(t-1)+\text { mass }(t) \text { for the current measurement }
$$

where mass $(t)$ is the percentage release at the time of measurement and $t-1$ is the percentage of the released drug at the previous timepoint.

For kinetic model fitting, we analyzed the data for release profiles using pharmacokinetics software (KinetDS3, developed at Jagiellonian University, Krakow, at the Faculty of Pharmacy's Department of Pharmaceutical Technology and Biopharmaceutics). The kinetic parameters identified were release rate (RR), release efficiency (RE), and mean dissolution time (MDT) [48].

\subsection{Antibacterial Evaluation Assays}

\subsubsection{In Vitro Antimicrobial Assay by the Log Reduction Method}

To evaluate the antimicrobial potential of NPs, we analyzed each component (functionalized ZnO NPs, nanoformulations, and PCA) using Staphylococcus aureus (S. aureus, ATCC 25923). Each ZnO NP, functionalized ZnO NP, and nanoformulation was immersed in the tryptic soy broth (TSB; Merck Millipore, Darmstadt, Germany) according to Kolmas et al. [49] to yield a final concentration of $8.3 \mathrm{mg} / \mathrm{mL}$ for $\mathrm{ZnO}$ NPs and modified 
$\mathrm{ZnO}$ NPs and $1.72 \mathrm{mg} / \mathrm{mL}$ for PCA (for nanoformulations). The samples were then incubated in a shaking water bath (Elpin+) at $100 \mathrm{rpm}$ and $37^{\circ} \mathrm{C}$ for three, five, or seven days. After incubation, the solutions in each glass bottle were transferred to a tube and centrifuged, and the supernatants were collected (with continually released PCA in the case of nanoformulations) to be used for antibacterial analysis. We inoculated the collected supernatants for the final bacterial concentration of $\sim 2 \times 10^{3}$ colony-forming units $(\mathrm{CFU}) / \mathrm{mL}$, followed by an 18 -h incubation at $37^{\circ} \mathrm{C}$. Next, $100-\mu \mathrm{L}$ samples withdrawn from the solutions were serially diluted and plated onto the TSB, followed by the second 18 -h incubation at $37^{\circ} \mathrm{C}$. After analysis and counting of the resulting bacterial colonies, we prepared two control samples: one with bacterial cells (negative control, $2 \times 10^{3} \mathrm{CFU} / \mathrm{mL}$ ) and the second with pure PCA $(1.72 \mathrm{mg} / \mathrm{mL})$. All the experiments were conducted in triplicate.

\subsubsection{Antimicrobial Activities by the Disc Diffusion Method}

The antimicrobial activities of $\mathrm{ZnO}$ NPs, functionalized $\mathrm{ZnO} N P s$, PCA, and nanoformulations were assessed as described below using the disc diffusion method. Each of the test materials was dispersed in $10 \mathrm{~mL}$ PBS for a final concentration of $8.3 \mathrm{mg} / \mathrm{mL}$ for $\mathrm{ZnO}$ NPs and $1.72 \mathrm{mg} / \mathrm{mL}$ for PCA. The dispersions were maintained at $37^{\circ} \mathrm{C}$ under shaking in a water bath at $100 \mathrm{rpm}$ and then centrifuged at $3500 \mathrm{rpm}$ for $5 \mathrm{~min}$ (MPW-54, MPW MED. Instruments, Warsaw, Poland). The supernatants drawn after this step were used in subsequent tests. For microbial suspensions of $\sim 10^{8} \mathrm{CFU} / \mathrm{mL}$, we used bacteria cultured overnight on solid media and inoculated onto agar plates with even spreading over the surface using a sterile swab. After $15 \mathrm{~min}$ of pre-incubation, 6-mm paper discs were impregnated with $20 \mu \mathrm{L}$ of the supernatants and placed over the inoculated area, followed by an 18 -h incubation at the temperature of $37^{\circ} \mathrm{C}$. After the incubation, we used calipers to measure the inhibition zone diameter on each plate. All the experiments were conducted in triplicate.

\subsubsection{Minimum Inhibitory Concentration (MIC) Determination}

We used a standard microdilution method to determine the MIC for S. aureus. Initial bacterial inocula $\left(5 \times 10^{5} \mathrm{CFU} / \mathrm{mL}\right.$ in the Mueller Hinton II Broth; Biomaxima, Lublin, Poland) were exposed in a 96-well plate to various dilutions of the supernatants (obtained after seven days of release of $\mathrm{ZnO} N P s$, functionalized $\mathrm{ZnO}$ NPs, PCA, and hybrid nanoformulations into the PBS) and incubated at $37^{\circ} \mathrm{C}$ for $18 \mathrm{~h}$. The broth containing only bacterial cells was used as the negative control. All the experiments were conducted in triplicate.

\subsection{Statistical Analysis}

We performed analysis of variance (ANOVA) with post-hoc adjustment (Tukey) on the values obtained as averages of three replicates, with one-way ANOVA for drug loading parameters. Data quality was assessed using the Brown-Forsythe test, and we evaluated distribution normality with the Shapiro-Wilk test. A $p \leq 0.05$ was set as the threshold for statistical significance, and all the analyses were conducted with Statistica (v. 13.1, StatSoft, Inc., Tulsa, OK, USA).

\section{Conclusions}

In this study, we produced hybrid antibacterial organic/inorganic nanoformulations by combining PCA and $\mathrm{ZnO}$ NPs functionalized by various organic silane groups. With this approach, we obtained a high PCA prodrug loading capacity of up to $\sim 18 \mathrm{wt} . \%$. In release tests, nanoformulations released only $\sim 8 \%$ of the loaded PCA after $96 \mathrm{~h}$, indicating a long-term release effect, with a rate that depended on the surface modification applied.

We evaluated the antibacterial and bactericidal effects of this nanoformulation against S. aureus using log reduction and disc diffusion assays. The antibacterial agent was tested using PBS solutions obtained after release, with separation of $\mathrm{ZnO} N P s$ and nanoformulations from the solution at predetermined time intervals of three, five, and seven days. A 
significant antibacterial and bactericidal effect was found for up to seven days of release, again, with the antibacterial effect depending on the surface modification of $\mathrm{ZnO}$ NPs. Results of the MIC assay gave clear evidence of improved antibacterial activity of hybrid nanoformulations against $S$. aureus, with hybrid nanoformulations exhibiting the lowest MIC values compared with $\mathrm{ZnO}$ NPs and functionalized $\mathrm{ZnO}$ NPs.

Overall, the hybrid organic/inorganic nanoformulation consisting of ZnO NPs loaded with PCA exhibited high long-term antibacterial and bactericidal effects against $S$. aureus. These findings suggest new possibilities for sustained antibacterial prodrug release in the treatment of bacterial infections and in antibacterial coatings beyond traditional approaches using $\mathrm{ZnO}$ NPs alone or free drugs.

Supplementary Materials: The following are available online at https:/ /www.mdpi.com/article/10 $.3390 /$ ijms22105287/s1, Figure S1: The elemental analysis by EDX of all the materials at different stages of preparation. In each material, we highlighted (in dotted-box) the element that should be seen in order to confirm the surface modification or PCA drug loading in the nanoformulations.

Author Contributions: Conceptualization, K.A.; methodology, K.A. and U.P.; formal analysis, K.A., A.S.-S. and U.P.; investigation, K.A., U.P., A.S.-S. and J.W.; resources, K.A., W.L., U.P. and A.H.H.E.-D.; writing-original draft preparation, K.A. (and some contribution by U.P.); writing-review and editing, K.A., A.S.-S., U.P., J.W. and W.L.; supervision, W.L. All authors have read and agreed to the published version of the manuscript.

Funding: We thank the National Research Centre (Egypt) and the Institute of High-Pressure Physics, Polish Academy of Sciences (Poland), for support of this work. Funding for equipment used in this research was provided by the CePT project (No. POIG.02.02.00-14-024/08) under the European Regional Development Fund within the Operational Program "Innovative Economy" for 2007-2013. The APC was funded by the Institute of High-Pressure Physics, Polish Academy of Sciences (Poland).

Institutional Review Board Statement: Not applicable.

Informed Consent Statement: Not applicable.

Data Availability Statement: Not applicable.

Acknowledgments: All of the XRD and FE-SEM analyses were performed by Stanislaw Gierlotka and Adam Presz, Laboratory of Nanostructures and Nanomedicine, Institute of HighPressure Physics, Polish Academy of Sciences.

Conflicts of Interest: The authors declare no conflict of interest.

\section{References}

1. Shrivastava, S.; Shrivastava, P.; Ramasamy, J. World health organization releases global priority list of antibiotic-resistant bacteria to guide research, discovery, and development of new antibiotics. J. Med. Soc. 2018, 32, 76-77. [CrossRef]

2. Mahavy, C.E.; Duez, P.; ElJaziri, M.; Rasamiravaka, T. African Plant-Based Natural Products with Antivirulence Activities to the Rescue of Antibiotics. Antibiotics 2020, 9, 830. [CrossRef] [PubMed]

3. Rossiter, S.E.; Fletcher, M.H.; Wuest, W.M. Natural Products as Platforms to Overcome Antibiotic Resistance. Chem. Rev. 2017, 117, 12415-12474. [CrossRef]

4. Haque, M.; Sartelli, M.; McKimm, J.; Abu Bakar, M. Health care-associated infections-An overview. Infect. Drug Resist. 2018, 11, 2321-2333. [CrossRef] [PubMed]

5. Corey, G.R. Staphylococcus aureus bloodstream infections: Definitions and treatment. Clin. Infect. Dis. 2009, 48 (Suppl. 4), S254-S259. [CrossRef]

6. Taylor, T.A.; Unakal, C.G. Staphylococcus Aureus. In StatPearls; StatPearls Publishing LLC.: Treasure Island, FL, USA, 2019.

7. Mama, M.; Aklilu, A.; Misgna, K.; Tadesse, M.; Alemayehu, E. Methicillin- and Inducible Clindamycin-Resistant Staphylococcus aureus among Patients with Wound Infection Attending Arba Minch Hospital, South Ethiopia. Int. J. Microbiol. 2019, 2019, 2965490. [CrossRef] [PubMed]

8. Dogan, M.; Isyar, M.; Yilmaz, I.; Bilir, B.; Sirin, D.Y.; Cakmak, S.; Mahirogullari, M. Are the leading drugs against Staphylococcus aureus really toxic to cartilage? J. Infect. Public Health 2016, 9, 251-258. [CrossRef]

9. Rayner, C.; Munckhof, W.J. Antibiotics currently used in the treatment of infections caused by Staphylococcus aureus. Intern. Med. J. 2005, 35, S3-S16. [CrossRef]

10. Kulkarni, A.P.; Nagvekar, V.C.; Veeraraghavan, B.; Warrier, A.R.; TS, D.; Ahdal, J.; Jain, R. Current Perspectives on Treatment of Gram-Positive Infections in India: What Is the Way Forward? Interdiscip. Perspect. Infect. Dis. 2019, 2019, 7601847. [CrossRef] 
11. Ann, L.C.; Mahmud, S.; Bakhori, S.K.M.; Sirelkhatim, A.; Mohamad, D.; Hasan, H.; Seeni, A.; Rahman, R.A. Antibacterial responses of zinc oxide structures against Staphylococcus aureus, Pseudomonas aeruginosa and Streptococcus pyogenes. Ceram. Int. 2014, 40, 2993-3001. [CrossRef]

12. Martinez-Gutierrez, F.; Olive, P.L.; Banuelos, A.; Orrantia, E.; Nino, N.; Sanchez, E.M.; Ruiz, F.; Bach, H.; Av-Gay, Y. Synthesis, characterization, and evaluation of antimicrobial and cytotoxic effect of silver and titanium nanoparticles. Nanomed. Nanotechnol. Biol. Med. 2010, 6, 681-688. [CrossRef]

13. Li, W.R.; Xie, X.B.; Shi, Q.S.; Duan, S.S.; Ouyang, Y.S.; Chen, Y.B. Antibacterial effect of silver nanoparticles on Staphylococcus aureus. Biometals 2011, 24, 135-141. [CrossRef] [PubMed]

14. Jesline, A.; John, N.P.; Narayanan, P.M.; Vani, C.; Murugan, S. Antimicrobial activity of zinc and titanium dioxide nanoparticles against biofilm-producing methicillin-resistant Staphylococcus aureus. Appl. Nanosci. 2015, 5, 157-162. [CrossRef]

15. Jones, N.; Ray, B.; Ranjit, K.T.; Manna, A.C. Antibacterial activity of ZnO nanoparticle suspensions on a broad spectrum of microorganisms. FEMS Microbiol. Lett. 2008, 279, 71-76. [CrossRef] [PubMed]

16. Siddiqi, K.S.; ur Rahman, A.; Husen, A. Properties of Zinc Oxide Nanoparticles and Their Activity Against Microbes. Nanoscale Res. Lett. 2018, 13, 141. [CrossRef] [PubMed]

17. Sirelkhatim, A.; Mahmud, S.; Seeni, A.; Kaus, N.H.M.; Ann, L.C.; Bakhori, S.K.M.; Hasan, H.; Mohamad, D. Review on Zinc Oxide Nanoparticles: Antibacterial Activity and Toxicity Mechanism. Nano Micro Lett. 2015, 7, 219-242. [CrossRef] [PubMed]

18. Martínez-Carmona, M.; Gun'ko, Y.; Vallet-Regí, M. ZnO Nanostructures for Drug Delivery and Theranostic Applications. Nanomaterials 2018, 8, 268. [CrossRef] [PubMed]

19. Tiwari, V.; Mishra, N.; Gadani, K.; Solanki, P.S.; Shah, N.A.; Tiwari, M. Mechanism of Anti-bacterial Activity of Zinc Oxide Nanoparticle against Carbapenem-Resistant Acinetobacter baumannii. Front. Microbiol. 2018, 9, 1218. [CrossRef]

20. Kaur, P.; Thakur, R.; Kumar, S.; Dilbaghi, N. Interaction Of ZnO Nanoparticles with Food Borne Pathogens Escherichia coli DH5 $\alpha$ and Staphylococcus aureus 5021 \& Their Bactericidal Efficacy. AIP Conf. Proc. 2011, 1393, 153-154. [CrossRef]

21. Patra, P.; Mitra, S.; Debnath, N.; Pramanik, P.; Goswami, A. Ciprofloxacin conjugated zinc oxide nanoparticle: A camouflage towards multidrug resistant bacteria. Bull. Mater. Sci. 2014, 37, 199-206. [CrossRef]

22. Iswarya, A.; Vaseeharan, B.; Anjugam, M.; Ashokkumar, B.; Govindarajan, M.; Alharbi, N.S.; Kadaikunnan, S.; Khaled, J.M.; Benelli, G. Multipurpose efficacy of $\mathrm{ZnO}$ nanoparticles coated by the crustacean immune molecule $\beta$-1, 3-glucan binding protein: Toxicity on HepG2 liver cancer cells and bacterial pathogens. Colloids Surf. B Biointerfaces 2017, 158, 257-269. [CrossRef]

23. Lee, J.; Choi, K.-H.; Min, J.; Kim, H.-J.; Jee, J.-P.; Park, B.J. Functionalized ZnO Nanoparticles with Gallic Acid for Antioxidant and Antibacterial Activity against Methicillin-Resistant S. aureus. Nanomaterials 2017, 7, 365. [CrossRef] [PubMed]

24. Choi, K.-H.; Nam, K.C.; Lee, S.-Y.; Cho, G.; Jung, J.-S.; Kim, H.-J.; Park, B.J. Antioxidant Potential and Antibacterial Efficiency of Caffeic Acid-Functionalized ZnO Nanoparticles. Nanomaterials 2017, 7, 148. [CrossRef] [PubMed]

25. Palanikumar, L.; Ramasamy, S.; Hariharan, G.; Balachandran, C. Influence of particle size of nano zinc oxide on the controlled delivery of Amoxicillin. Appl. Nanosci. 2013, 3, 441-451. [CrossRef]

26. Khan, A.K.; Rashid, R.; Fatima, N.; Mahmood, S.; Mir, S.; Khan, S.; Jabeen, N.; Murtaza, G. Pharmacological Activities of Protocatechuic Acid. Acta Pol. Pharm. 2015, 72, 643-650.

27. Kakkar, S.; Bais, S. A review on protocatechuic Acid and its pharmacological potential. ISRN Pharmacol. 2014, $2014,952943$. [CrossRef] [PubMed]

28. Stojković, D.S.; Živković, J.; Soković, M.; Glamočlija, J.; Ferreira, I.C.F.R.; Janković, T.; Maksimović, Z. Antibacterial activity of Veronica montana L. extract and of protocatechuic acid incorporated in a food system. Food Chem. Toxicol. 2013, 55, 209-213. [CrossRef]

29. Miklasińska, M.; Kępa, M.; Wojtyczka, R.D.; Idzik, D.; Zdebik, A.; Orlewska, K.; Wasik, T.J. Antibacterial Activity of Protocatechuic Acid Ethyl Ester on Staphylococcus aureus Clinical Strains Alone and in Combination with Antistaphylococcal Drugs. Molecules 2015, 20, 13536-13549. [CrossRef]

30. Mandalari, G.; Bisignano, C.; D’Arrigo, M.; Ginestra, G.; Arena, A.; Tomaino, A.; Wickham, M.S.J. Antimicrobial potential of polyphenols extracted from almond skins. Lett. Appl. Microbiol. 2010, 51, 83-89. [CrossRef]

31. Chao, C.Y.; Yin, M.C. Antibacterial Effects of Roselle Calyx Extracts and Protocatechuic Acid in Ground Beef and Apple Juice. Foodborne Pathog. Dis. 2009, 6, 201-206. [CrossRef]

32. Barahuie, F.; Hussein, M.Z.; Hussein-Al-Ali, S.H.; Arulselvan, P.; Fakurazi, S.; Zainal, Z. Preparation and controlled-release studies of a protocatechuic acid-magnesium/aluminum-layered double hydroxide nanocomposite. Int. J. Nanomed. 2013, 8 , 1975-1987. [CrossRef] [PubMed]

33. Usman, M.S.; Hussein, M.Z.; Kura, A.U.; Fakurazi, S.; Masarudin, M.J.; Ahmad Saad, F.F. Graphene Oxide as a Nanocarrier for a Theranostics Delivery System of Protocatechuic Acid and Gadolinium/Gold Nanoparticles. Molecules 2018, 23, 500. [CrossRef] [PubMed]

34. Wojnarowicz, J.; Chudoba, T.; Gierlotka, S.; Lojkowski, W. Effect of Microwave Radiation Power on the Size of Aggregates of ZnO NPs Prepared Using Microwave Solvothermal Synthesis. Nanomaterials 2018, 8, 343. [CrossRef]

35. Wojnarowicz, J.; Chudoba, T.; Koltsov, I.; Gierlotka, S.; Dworakowska, S.; Lojkowski, W. Size control mechanism of ZnO nanoparticles obtained in microwave solvothermal synthesis. Nanotechnology 2018, 29, 065601. [CrossRef] 
36. Wojnarowicz, J.; Opalinska, A.; Chudoba, T.; Gierlotka, S.; Mukhovskyi, R.; Pietrzykowska, E.; Sobczak, K.; Lojkowski, W. Effect of Water Content in Ethylene Glycol Solvent on the Size of ZnO Nanoparticles Prepared Using Microwave Solvothermal Synthesis. J. Nanomater. 2016, 2016, 2789871. [CrossRef]

37. Baghdadi, Y.N.; Youssef, L.; Bouhadir, K.; Harb, M.; Mustapha, S.; Patra, D.; Tehrani-Bagha, A.R. The effects of modified zinc oxide nanoparticles on the mechanical/thermal properties of epoxy resin. J. Appl. Polym. Sci. 2020, 137, 49330. [CrossRef]

38. Barahuie, F.; Hussein, M.Z.; Gani, S.A.; Fakurazi, S.; Zainal, Z. Synthesis of protocatechuic acid-zinc/aluminium-layered double hydroxide nanocomposite as an anticancer nanodelivery system. J. Solid State Chem. 2015, 221, 21-31. [CrossRef]

39. Meißner, T.; Oelschlägel, K.; Potthoff, A. Implications of the stability behavior of zinc oxide nanoparticles for toxicological studies. Int. Nano Lett. 2014, 4, 116. [CrossRef]

40. Luo, M.; Shen, C.; Feltis, B.N.; Martin, L.L.; Hughes, A.E.; Wright, P.F.A.; Turney, T.W. Reducing ZnO nanoparticle cytotoxicity by surface modification. Nanoscale 2014, 6, 5791-5798. [CrossRef]

41. Pokrowiecki, R.; Wojnarowicz, J.; Zareba, T.; Koltsov, I.; Lojkowski, W.; Tyski, S.; Mielczarek, A.; Zawadzki, P. Nanoparticles And Human Saliva: A Step Towards Drug Delivery Systems For Dental and Craniofacial Biomaterials. Int. J. Nanomed. 2019, 14, 9235-9257. [CrossRef]

42. Halbus, A.F.; Horozov, T.S.; Paunov, V.N. Surface-Modified Zinc Oxide Nanoparticles for Antialgal and Antiyeast Applications. ACS Appl. Nano Mater. 2020, 3, 440-451. [CrossRef]

43. Usman, M.S.; Hussein, M.Z.; Kura, A.U.; Fakurazi, S.; Masarudin, M.J.; Saad, F.F.A. Synthesis and characterization of protocatechuic acid-loaded gadolinium-layered double hydroxide and gold nanocomposite for theranostic application. Appl. Nanosci. 2018, 8, 973-986. [CrossRef]

44. Cierech, M.; Wojnarowicz, J.; Kolenda, A.; Krawczyk-Balska, A.; Prochwicz, E.; Woźniak, B.; Łojkowski, W.; MierzwińskaNastalska, E. Zinc Oxide Nanoparticles Cytotoxicity and Release from Newly Formed PMMA-ZnO Nanocomposites Designed for Denture Bases. Nanomaterials 2019, 9, 1318. [CrossRef] [PubMed]

45. Souza, R.C.d.; Haberbeck, L.U.; Riella, H.G.; Ribeiro, D.H.B.; Carciofi, B.A.M. Antibacterial activity of zinc oxide nanoparticles synthesized by solochemical process. Braz. J. Chem. Eng. 2019, 36, 885-893. [CrossRef]

46. Abraham, S.N.; Beachey, E.H.; Simpson, W.A. Adherence of Streptococcus pyogenes, Escherichia coli, and Pseudomonas aeruginosa to fibronectin-coated and uncoated epithelial cells. Infect. Immun. 1983, 41, 1261-1268. [CrossRef] [PubMed]

47. Lallo da Silva, B.; Abuçafy, M.P.; Berbel Manaia, E.; Oshiro Junior, J.A.; Chiari-Andréo, B.G.; Pietro, R.C.R.; Chiavacci, L.A. Relationship between Structure and Antimicrobial Activity of Zinc Oxide Nanoparticles: An Overview. Int. J. Nanomed. 2019, 14, 9395-9410. [CrossRef] [PubMed]

48. Ammar, H.O.; Ghorab, M.M.; Mahmoud, A.A.; Higazy, I.M. Lamotrigine loaded poly-varepsilon-(d,1-lactide-co-caprolactone) nanoparticles as brain delivery system. Eur. J. Pharm. Sci. Off. J. Eur. Fed. Pharm. Sci. 2018, 115, 77-87. [CrossRef]

49. Kolmas, J.; Groszyk, E.; Piotrowska, U. Nanocrystalline hydroxyapatite enriched in selenite and manganese ions: Physicochemical and antibacterial properties. Nanoscale Res. Lett. 2015, 10, 278. [CrossRef] [PubMed] 